\title{
AS REPRESENTAÇÕES DA CATEQUESE JESUÍTICA NOS LIVROS DO PNLD: ABORDAGENS DO PASSADO COLONIAL E POSSIBILIDADES DE APRENDIZAGEM HISTÓRICA
}

\author{
Camila Corrêa e Silva de Freitas ${ }^{1}$
}

\begin{abstract}
Resumo: O texto que ora se apresenta visa problematizar as narrativas didáticas sobre o período colonial brasileiro tomando como tema de entrada a atuação da Companhia de Jesus, e tomando como fontes de análise os livros de História do $7^{\circ}$ ano das três coleções didáticas mais distribuídas para os alunos dos anos finais do Ensino Fundamental nas edições de 2017 e 2020. Objetivamos investigar e analisar o diálogo entre a historiografia acadêmica e a historiografia escolar sobre a América portuguesa, tanto em relação aos conteúdos históricos apresentados quanto às abordagens historiográficas adotadas; identificar e analisar os sentidos atribuídos ao passado colonial pelos livros didáticos selecionados; e, ainda, refletir sobre as possibilidades de aprendizagem histórica oferecidas por essas narrativas.

Palavras-chave: Período colonial. Catequese jesuítica. Livro didático. PNLD. Aprendizagem histórica.

\section{THE REPRESENTATIONS OF JESUIT CATECHESIS IN PNLD BOOKS: APPROACHES TO THE COLONIAL PAST AND POSSIBILITIES OF HISTORICAL LEARNING}

\begin{abstract}
The text presented here aims to problematize the didactic narratives about the Brazilian colonial period taking as input the performance of the "Companhia de Jesus", and taking as sources of analysis the books of History of the 7th year of the three most distributed didactic collections for students in the final years of an elementary school in the 2017 and 2020 editions. We aim to investigate and analyze the dialogue between academic historiography and school historiography about Portuguese America, both with the historical contents presented and to the historiographic approaches adopted; identify and analyze the meanings attributed to the colonial past by the selected didactics books; and, still, reflect on the possibilities of historical learning offered by these narratives.

Keywords: Colonial period. Jesuit catechesis. Didactic book. PNLD. Historical learning.

\section{LES REPRÉSENTATIONS DE LA CATÉCHÈSE JÉSUITE DANS LES LIVRES PNLD: APPROCHES DU PASSÉ COLONIAL ET POSSIBILITÉS D'APPRENTISSAGE HISTORIQUE}

Resumé: Le texte présenté ici vise à problématiser les récits didactiques sur la période coloniale brésilienne en prenant comme intrant la performance de la Compagnie de Jésus, et en prenant comme sources d'analyse les livres d'histoire de la 7e année des trois collections didactiques les plus distribuées aux étudiants de le dernières années d'école primaire aux éditions 2017 et 2020. Nous visons à enquêter et à analyser le dialogue entre l'historiographie académique et l'historiographie scolaire sur l'Amérique portugaise, tant par rapport au contenu historique présenté que par les approches historiographiques adoptées; identifier et analyser les significations attribuées au passé colonial par les manuels sélectionnés; et, encore, réfléchir sur les possibilités d'apprentissage historique offertes par ces récits.

Mots-clés: Période coloniale. Catéchèse jésuite. Cahier de texte. PNLD. Apprentissage historique.

\footnotetext{
1 Possui graduação em História pela Universidade Federal do Rio de Janeiro (2007), mestrado em História Social pela mesma universidade (2010) e doutorado em História Social pela Universidade de São Paulo (2017). Atualmente é professora substituta da Universidade Federal de Pernambuco.
} 


\section{LAS REPRESENTACIONES DE LA CATEQUESIS JESUÍTICA EN LOS LIBROS DEL PNLD: ENFOQUES DEL PASADO COLONIAL Y POSIBILIDADES DE APRENDIZAJE HISTÓRICO}

Resumen: El texto presentado aquí tiene como objetivo problematizar las narrativas didácticas sobre el período colonial brasileño, tomando como entrada la actuación de la Compañía de Jesús y, como fuentes de análisis, los libros de Historia del séptimo año de las tres colecciones didácticas más distribuidas a los estudiantes de los últimos años de la escuela primaria, en las ediciones de 2017 y 2020. Nuestro objetivo es investigar y analizar el diálogo entre la historiografía académica y la historiografía escolar sobre la América portuguesa, en relación con el contenido histórico presentado y con los enfoques historiográficos adoptados; identificar y analizar los significados atribuidos al pasado colonial por los libros de texto seleccionados; y, por fin, reflexionar sobre las posibilidades de aprendizaje histórico ofrecidas por estas narrativas.

Palabras-clave: Período colonial. Catequesis jesuítica. Libro de texto. PNLD. Aprendizaje histórico.

\section{Introdução}

O texto que ora se apresenta é o primeiro fruto de um projeto de pesquisa intitulado "As representações da Companhia de Jesus na historiografia escolar brasileira (séculos XX e XXI)". Em sua primeira fase, o objeto de investigação sobre o qual nos detivemos foi a caracterização da atuação dos jesuítas na América portuguesa apresentada pelos livros didáticos de História distribuídos pelo Programa Nacional do Livro e do Material Didático (PNLD) no século XXI, mais especificamente pelos livros do $7^{\circ}$ ano (série à qual a Base Nacional Comum Curricular atribui tal temática). Das coleções didáticas disponibilizadas pelo programa para alunos do Ensino Fundamental Anos Finais nas suas duas últimas edições (2017 e 2020), escolhemos analisar os livros do $7^{\circ}$ ano das três mais distribuídas ${ }^{2}$. Nosso objetivo geral consistia na problematização da literatura didática que trata do período colonial, utilizando-nos do tema da presença e atuação da Companhia de Jesus na América portuguesa como "porta de entrada" para cumprir três objetivos específicos: investigar e analisar o diálogo entre a historiografia acadêmica e a historiografia escolar sobre a América lusa, tanto em relação aos conteúdos históricos apresentados quanto às abordagens historiográficas adotadas; identificar e analisar os sentidos atribuídos ao passado colonial pelos livros didáticos selecionados; e, ainda, refletir sobre as possibilidades de aprendizagem histórica oferecidas por essas narrativas. São os resultados iniciais dessa pesquisa que nos propomos a apresentar.

\footnotetext{
${ }^{2}$ Estas são: BOULOS JÚNIOR, 2018; EDITORA MODERNA, 2018; DIAS, 2018.
} 
E por que, dentre tanto temas possíveis abordados pelos livros didáticos de História, escolher este relativo à atuação dos missionários no período colonial? E por que nesses livros em específico?

Tradicionalmente, o grande tema da colonização portuguesa na América, tema guarda-chuva para tantos outros, é significado nos manuais didáticos de História como um período de formação da sociedade brasileira, em suas estruturas políticas, econômicas e culturais. Tal processo histórico seria protagonizado pela Coroa portuguesa e seus representantes na colônia americana, sendo outros sujeitos secundarizados, ou mesmo apagados do processo histórico. A colonização, entendido como lugar histórico originário da sociedade brasileira, seria resultado da realização das ações, interesses e projetos dos lusos em uma América disponível para a empreitada, sem grandes empecilhos.

Tal interpretação foi forjada nas primeiras grandes obras sobre a formação histórica do Brasil enquanto nação e sociedade, as de Francisco Varnhagen (1854-1857) e de Capistrano de Abreu (1907), ainda que estas variem quanto ao protagonismo português. O sentido seminal e basilar, e determinista em alguns autores, atribuído à época colonial para a compreensão da sociedade brasileira se perpetuou nas interpretações de Gilberto Freyre, Sérgio Buarque de Holanda e Caio Prado Júnior na primeira metade do século XX, que marcaram por muito tempo as nossas concepções sobre o nosso passado colonial. Se na pesquisa histórica estas interpretações já foram problematizadas e, em certa medida, superadas, na literatura didática do século XXI elas vêm gozando de longevidade. Em estudo recente, o professor Mauro Cezar Coelho demonstrou como seis livros do $7^{\circ}$. ano, publicados entre 2007 e 2009, pertencentes a coleções avaliadas e distribuídas pelo PNLD, continuavam a reproduzir uma narrativa consagrada pela tradição, isto é, a de que no período colonial se encontram as origens das nossas estruturas sociais, econômicas, políticas e culturais, e que a colonização foi um processo histórico protagonizado pela Coroa portuguesa e seus representantes atuantes na colônia americana ${ }^{3}$.

Assim, a análise da caracterização e da atuação dos missionários, em particular dos jesuítas, que desempenharam um papel central na viabilização da empresa de

\footnotetext{
${ }^{3}$ Os seis livros didáticos em questão são os seguintes: Projeto Araribá; História sociedade \& cidadania; História: conceitos e procedimentos; Navegando pela História; História: da baixa Idade Média ao pensamento iluminista; História: das cavernas ao terceiro milênio: da formação da Europa medieval à colonização do continente americano.
} 
colonização portuguesa na América, pode servir como bússola de transformações e manutenções na historiografia escolar chancelada pelo PNLD.

Por outro lado, a escolha dos livros didáticos de História do $7^{\circ}$ ano mais distribuídos nas escolas públicas do país como corpus documental de análise se justifica por dois pressupostos. O primeiro diz respeito aos próprios objeto e objetivos desta pesquisa, que partem da compreensão dos livros didáticos como referências importantes na construção do saber histórico escolar, tanto por professores quanto por alunos. É claro que outras referências e saberes são mobilizados nessa construção, sobretudo nos tempos correntes de intensificação da disputa de narrativas sobre o passado, potencializada pelo uso das mídias digitais na sua divulgação. Porém, e principalmente na escola pública brasileira, que atende geralmente aos setores mais pobres da nossa sociedade, cujo acesso ainda restrito a fontes variadas de informações, o livro didático continua sendo um recurso fundamental e bastante mobilizado pelas professoras e professores para promover um processo de ensino e aprendizagem da História.

A influência exercida pelos livros didáticos avaliados pelo PNLD na apreensão dos conhecimentos históricos e, portanto, na construção dos saberes históricos escolares pelos alunos é potencializada pela sua distribuição gratuita. E esta não é, em termos numéricos, pouco relevante. Daí constituir um segundo pressuposto importante para a nossa escolha. A coleção "História sociedade \& cidadania", de autoria de Alfredo Boulos Júnior e editada pela FTD, foi a mais distribuída pelas edições do PNLD de 2017 e $2020^{4}$. Naquele, um total de 3.313.449 livros do aluno desta coleção foram distribuídos para o Ensino Fundamental - Anos Finais em todo o país, dos quais 860.997 eram livros de História do $7^{\circ}$.ano. Em 2020, o total subiu para 3.571.389, sendo 933.313 livros do $7^{\circ}$.ano. As segunda e terceira coleções mais distribuídas, apesar de corresponderem à metade e a um terço do total de livros distribuídos da coleção "História sociedade \& cidadania", somam números bastante consideráveis. Os livros da coleção "Projeto Araribá: história", segunda mais distribuída, e cujo nome foi modificado para "Araribá mais: história" no PNLD 2020, somaram uma média total de distribuição, considerando os números de 2017 e 2020, de 1.750 .000 livros do aluno por edição do Programa, dos quais um média de 450.000 foram para o $7^{\circ}$ ano. Já os da terceira coleção mais distribuída, "Vontade de Saber: história", variaram em um total de

\footnotetext{
${ }^{4}$ Quando da produção deste artigo, o processo de escolha dos livros didáticos pelas escolas públicas em 2020 ainda não havia se encerrado, mas 90\% delas já haviam finalizado seus pedidos ao PNLD. Disponível em: http://simec.mec.gov.br/livros/publico/index_acompanhamento.php. Acesso em: 18 jun. 2020.
} 
800 mil a 1 milhão de livros do aluno distribuídos em cada uma das últimas edições do Programa, e somaram uma média de 250.000 livros de História para o $7^{\circ}$.ano por edição do PNLD 5 .

Deste modo, estamos tratando de narrativas didáticas que têm chegado literalmente a milhares de alunas e alunos brasileiros. Parece, portanto, relevante nos determos na análise dessas narrativas e dos sentidos atribuídos ao passado pelas mesmas.

Em termos metodológicos, algumas questões-chave guiaram a nossa análise inicial. Procuramos identificar e analisar comparativamente: qual/quais eram as características e posicionamentos gerais atribuídos aos jesuítas; qual/quais atividades (religiosas ou não) lhes eram associadas; e como se davam as relações dos missionários com três grupos sociais, arbitrariamente generalizados, que integraram e atuaram intensamente no processo de formação e desenvolvimento da América portuguesa: os representantes da Coroa lusa, os colonos e os indígenas.

Cabe, por fim, esclarecer que serão analisados os três livros didáticos do $7^{\circ}$ ano avaliados e distribuídos pelo PNLD 2020, publicados em 2018. Isto porque, apesar das edições dos livros das coleções "Projeto Araribá: História" e "Vontade de Saber: história" terem mantido seu conteúdo anterior (edição de 2015 aprovada pelo PNLD 2017), o conteúdo do livro do $7^{\circ}$ ano da coleção "História sociedade \& cidadania" foi modificado em relação à edição anterior.

\section{A formação da América portuguesa e a atuação dos missionários jesuítas nos livros do PNLD (2020)}

Tendo orientado a análise dos três livros didáticos comparativamente, cabe apresentar os aspectos semelhantes e diferentes observados nos seus conteúdos e abordagens. Iniciaremos pelos elementos semelhantes às três narrativas, passando posteriormente para as variações e diferenças mais marcantes.

De maneira geral, a caracterização dos padres da Companhia de Jesus como grupo social se baseia em dois compromissos religiosos e morais que identificariam o mesmo na história do mundo moderno e na história da América portuguesa: a difusão do cristianismo católico no ultramar europeu (África, Ásia e América) e a proteção dos índios contra a escravização empreendida pelos colonos portugueses. Quanto às suas

\footnotetext{
5 Disponível em: https://www.fnde.gov.br/index.php/programas/programas-do-livro/pnld/dados-
} estatisticos. Acesso em: 18 jun. 2020. 
atividades na colônia, apesar das variações, que trataremos adiante, a principal que lhe é atribuída é a catequese. Esta, no entanto, assume duplo sentido: tanto o de doutrinação religiosa, quanto, e principalmente, o sentido de "civilização", termo que, no contexto histórico das conquistas ou invasões europeias às Américas, significa promover um processo de inserção, subjugação e dominação cultural, civil e política dos ameríndios à cultura católica europeia e à autoridade do governo português. O principal espaço onde a tarefa catequética se dava eram os aldeamentos, locais administrados pelos missionários que aparentemente reproduziam a dinâmica espacial de uma aldeia indígena, mas não as dinâmicas sociais ou culturais.

No livro "Vontade de Saber: história", observamos as seguintes passagens: “Além desses funcionários, vieram com Tomé de Souza alguns padres jesuítas, que tinham como objetivo converter os indígenas ao catolicismo". (DIAS, 2018, p. 166); "Nas missões, os indígenas aprendiam a língua e os costumes portugueses, além de realizarem vários trabalhos agrícolas e artesanais" (DIAS, 2018, p. 168); "Muitos indígenas foram escravizados e mortos ao longo do processo colonizador do Brasil.[...] outros eram capturados pelos colonizadores e incorporados à sociedade colonial, por meio da catequização e do aldeamento nas missões religiosas” (DIAS, 2018, p. 202).

É possível perceber como o significado da catequese realizada nos aldeamentos como processo de inserção, enquadramento cultural (pela língua, costumes, religião e trabalho) e dominação política (uma vez que, nos aldeamentos, obedeciam aos padres, representantes da autoridade da Igreja e da Coroa) vai sendo construído ao longo das páginas que tratam do período colonial.

De fato, é através de diferentes significações atribuídas à catequese e ao espaço do aldeamento que a literatura didática caracteriza as relações dos jesuítas com os três grupos sociais que consideramos: os representantes da Coroa portuguesa, os colonos e os indígenas:

A ordem religiosa dos jesuítas foi um importante instrumento para a expansão do Império português e da Igreja católica na América. [...] os jesuítas se engajaram no projeto colonizador português, desenvolvendo ações missionárias com as populações nativas da Ásia, da África e da América. (EDITORA MODERNA, 2018, p. 180)

O trecho, que se encontra no livro da coleção “Araribá mais: história”, evidencia a perspectiva da instrumentalização das ações missionárias em prol do projeto colonizador da Coroa portuguesa, isto é, de consolidação do domínio luso sobre o 
território e as populações nativas americanas e a sua expansão. Esta abordagem é comum às três obras. As poucas outras atividades que são atribuídas aos jesuítas, como a criação de colégios em vilas e cidades e missões itinerantes, são apresentadas nessa chave interpretativa: "além disso, a catequização dos indígenas era vista pela Coroa portuguesa como uma forma de garantir a posse da região por meio da "pacificação" de grupos hostis, que se tornariam aliados na luta contra invasores, como ingleses, franceses e holandeses" (EDITORA MODERNA, 2018, p. 183).

Em 1554, os jesuítas fundaram um colégio no planalto, longe do litoral, com a intenção de catequizar os indígenas que viviam na região. A ocupação $e$ o povoamento dessa região do interior também ajudaram na defesa e na posse do território por Portugal. O povoado que se desenvolveu ao redor desse colégio deu origem à cidade de São Paulo. [...] Após sua passagem por São Paulo, Anchieta trabalhou em diferentes localidades do Brasil, como Rio de Janeiro, Espírito Santo e Bahia, dirigindo colégios, auxiliando a fundação de povoados e ensinando [...] (DIAS, 2018, p. 169)

Ao sobrepor a tarefa catequética à da ocupação e defesa territorial, e à tarefa da incorporação proveitosa e subjugação dos nativos aos portugueses, a literatura didática faz dos jesuítas agentes da colonização, e da missionação uma atividade que viabiliza e expande a mesma, uma vez que faz dos padres os principais mediadores entre nativos e portugueses. A sua atuação está sempre a serviço dos projetos e interesses da Coroa, protagonista desse processo histórico. Não por acaso, a primeira menção aos jesuítas nas três narrativas é sempre quando da chegada do primeiro governador geral, Tomé de Souza, em 1549.

Isto ocorre não só por conta da preocupação em oferecer conhecimentos consolidados cientificamente pela pesquisa histórica, mas sobretudo para marcar na narrativa sobre o passado o lugar histórico que está sendo atribuído àqueles sujeitos: o de colaboradores da empresa colonial encabeçada pela monarquia lusa, que assume mais diretamente a empreitada justamente com a criação do governo geral. A aliança se materializa tanto pela catequese nos aldeamentos enquanto processo civilizatório, leiase, de pacificação, subjugação e inserção dos nativos, quanto pelos avanços missionários para o interior, que “[...] ajudaram na defesa e posse do território por Portugal". Os três livros, portanto, em diferentes graus, dão continuidade à interpretação tradicional, muito presente na historiografia de filiação marxista e estruturalista dos anos 1970, que apresenta a Igreja colonial e seus agentes como braços da dominação política e ideológica das metrópoles europeias sobre as colônias americanas. 
A caracterização da catequese e do aldeamento, porém, descritos nas narrativas didáticas enquanto tarefa e espaço de dominação dos nativos pelos jesuítas, também determinam um outro tipo de relação social dos padres, dessa vez negativa, com os colonos:

Os jesuítas se opunham à escravização dos indígenas e defendiam que eles fossem reunidos nas missões para serem catequizados. Desde o início da colonização, os colonos portugueses escravizaram milhares de indígenas, que foram obrigados a realizar tarefas árduas no dia a dia dos canaviais. A maioria dos indígenas, no entanto, nunca aceitou essa situação. 'Descontentes, queimaram engenhos, acabaram com roças e povoados, obrigando os portugueses a recuar e fugir [...]'. Preocupados, os donatários solicitaram a ajuda do rei de Portugal, informando-lhe que, se não enviasse reforços, as capitanias corriam sério risco de serem destruídas. A maioria dos jesuítas era contra a escravização de povos nativos, e fizeram forte oposição a todos aqueles que utilizavam a mão de obra indígena escrava. (DIAS, 2018, p. 168)

Os aldeamentos jesuítas, por outro lado, serviam de proteção aos indígenas contra os exploradores interessados em escravizá-los. [...] $\mathrm{Na}$ América portuguesa, houve inúmeros conflitos entre jesuítas e colonos pelo controle sobre as populações indígenas. Enquanto os colonos visavam explorar a mão de obra indígena por meio da escravização, os jesuítas, como vimos, buscavam convertê-los ao cristianismo e transformá-los em 'bons cristãos'. (EDITORA MODERNA, 2018, p. 182-183)

Podemos deduzir dos trechos acima algumas interpretações iniciais das representações de jesuítas e colonos construídas pela literatura didática e das significações complementares atribuídas à catequese. A relação construída entre os dois grupos é intrinsecamente dicotômica e conflituosa, pois os colonos são caracterizados negativamente ao buscarem escravizar e explorar duramente os indígenas e se oporem, portanto, aos aldeamentos, os quais atacam para capturar e escravizar indígenas aldeados. Por outro lado, os jesuítas são caracterizados positivamente por defenderem a liberdade dos indígenas, uma vez que se opõem à sua escravização. A atividade da catequese ganha, assim, mais um significado, o da liberdade, pois que é apresentada como alternativa à escravidão, enquanto os aldeamentos passam a denotar também espaços de proteção. A subjugação e dominação cultural e política impostas via catequese nos aldeamentos não comprometem, na perspectiva dessas narrativas, o seu caráter positivo, nem constituem uma contradição aos sentidos de liberdade e proteção que se somam, pois que transformaria os nativos em "bons cristãos", uma alternativa sem dúvida bem melhor do que a de ser escravizado.

Por fim, a catequese também é significada, nas relações entre missionários e indígenas, como um processo de desorganização/destruição da cultura indígena. Porém, 
enquanto lemos no livro "Vontade de Saber" que "A catequização dos indígenas, no entanto, acabou modificando seu modo de vida e desorganizando suas sociedades" (DIAS, 2018, p. 168), o livro "Araribá mais: história" afirma que "A colonização portuguesa e a ação missionária dos jesuítas causaram profundos impactos aos povos indígenas que já viviam nas terras que hoje formam o Brasil. Os missionários impunham aos indígenas um modo de vida cristão e condenavam suas práticas e crenças tradicionais" (EDITORA MODERNA, 2018, p. 182). Contudo, lemos no livro do $7^{\circ}$.ano da coleção "História sociedade \& cidadania" que "Nas missões, os indígenas cultivavam cereais, frutas e erva-mate [...]. E tinham também um tempo reservado ao lazer e ao estudo". (BOULOS JÚNIOR, 2018, p. 224).

Ou seja, há uma significativa variância na abordagem dos impactos da catequese sobre as populações nativas e uma certa tendência à eufemização e mesmo positivação de um processo de violenta imposição cultural. Isso decorre das diferentes abordagens historiográficas e sentidos atribuídos ao passado que as obras didáticas aqui analisadas assumiram e expressaram em suas narrativas.

\section{Problematizando a historiografia escolar}

De fato, é partindo das variâncias e diferenças mais evidentes na abordagem da atuação dos jesuítas e das suas relações com diferentes grupos que podemos identificar filiações teóricas e historiográficas diversas.

É certo que os três livros apresentam os missionários como colaboradores do projeto colonizador da Coroa lusa, afinal ela continua sendo a grande protagonista desse processo histórico. A predominância das dimensões econômica e político-administrativa nos primeiros capítulos sobre a época colonial se evidencia nas temáticas abordadas (o cultivo da cana, a economia açucareira, a escravização africana, a administração da colônia, capitanias hereditárias, governo geral). E nesse sentido podemos apontar uma certa continuidade da influência da historiografia econômico-social que predominou no campo da pesquisa acadêmica entre os anos 1950 e 1970, e que ainda hoje se desenvolve com vigor, tendo sido notável a influência da abordagem marxista da História e da obra de Caio Prado Júnior no que tange a análise do processo de formação histórica do Brasil. Esta influência, muito marcante na historiografia escolar dos anos 1980 e 1990, foi matizada no século XXI, mas continua presente. Isto é, as ações dos colonizadores, a caracterização dos sujeitos e de suas relações, de conflito, aliança ou subjugação, a estruturação social hierarquizada, todos esses aspectos são determinados 
pela lógica de exploração econômica do território. Não por acaso tantas páginas são dedicadas à descrição dos engenhos de açúcar e de outras atividades e produtos cultivados ou extraídos da terra. É evidente que, na narrativa didática, particularmente no livro de Alfredo Boulos, o sentido mercantil da colonização continua predominando na interpretação do passado colonial.

Dessa forma, e aqui nos referimos especificamente à narrativa de Boulos marcando uma diferença de sua obra, os agentes religiosos, bem como a dimensão cultural, quase não têm lugar na sociedade colonial, formada por senhores de engenho, lavradores de cana, comerciantes, trabalhadores assalariados e escravizados indígenas e africanos. Os jesuítas são citados na chegada do primeiro governador geral e só voltam a aparecer no capítulo sobre a expansão territorial:

Os jesuítas vieram para o Brasil em 1549, acompanhando o primeiro governador-geral, Tomé de Sousa, e dedicaram-se ao ensino da religião cristã e à formação de crianças. Para isso, fundaram colégios nas principais vilas e cidades do litoral brasileiro. No litoral, as doenças e as guerras contra os colonizadores mataram milhares de indígenas; e aqueles que não morreram refugiaram-se no interior. Os jesuítas, então, também foram para o interior e lá criaram missões (grandes aldeamentos indígenas). [...] Nas missões, os indígenas cultivavam cereais, frutas e erva-mate; extraíam da floresta cacau, baunilha, guaraná e plantas medicinais; produziam tecidos, mobílias e esculturas de madeira, etc. Vários desses produtos eram exportados para a Europa, com grande lucro. E tinham também um tempo reservado ao lazer e ao estudo. Povoando vários pontos do interior brasileiro, as missões jesuíticas contribuíram para a ampliação e a conquista do território da América portuguesa. (EDITORA MODERNA, 2018, p. 223-224)

A menção pontual e irrelevante no desenvolvimento da narrativa sobre a atuação pedagógica e, portanto, cultural dos padres junto aos filhos dos colonos reforça a nossa hipótese da minimização dessa dimensão na concepção apresentada sobre a vida na colônia, dimensão entendida aqui como as diferentes formas de ser, viver e se expressar em sociedade. As exceções são os capítulos sobre os africanos no Brasil e sobre a invasão holandesa.

Curiosamente, a missionação e a catequese nos aldeamentos são caracterizadas como atividades menos associadas à uma doutrinação religiosa e a um enquadramento cultural e mais articuladas a atividades de exploração econômica e à expansão territorial, ainda que nas orientações ao professor haja a indicação de que se destaque seus propósitos religiosos e de integração cultural e política dos nativos. Mesmo não sendo explícita a articulação entre a atuação missionária e o projeto colonizador 
português, o sentido econômico daquela parece se sobrepor ao político-cultural, o que é coerente com a abordagem histórica do autor.

Por fim, apesar de as ações dos jesuítas colaborarem para a colonização, estes não são representados como seus agentes, nem no processo de expansão territorial, movimento do qual participam por questões religiosas - "[...] foram para o interior e lá criaram missões [...]”. Ajudar na expansão da ocupação e ampliação do domínio luso parece constituir um efeito colateral aparentemente fora do horizonte dos jesuítas. Isso, contudo, não altera o lugar histórico reservado a eles de colaboradores. No que diz respeito aos indígenas, o livro apresenta anteriormente resistências dos mesmos à escravidão, mas não à catequese, a qual parecem aceitar pacificamente, como sugere o trecho acima.

Desta análise, nos parece coerente afirmar que, na narrativa didática do livro "História sociedade \& cidadania", as perspectivas interpretativas privilegiadas são as econômicas e as político-administrativas. A ausência de conteúdos mais extensos que tratem das populações nativas, das formas de interação, conflito e acomodação delas com os portugueses, inclusive com os missionários, destes com os colonos, e do sentido civilizatório da catequese são indícios da marginalização do aspecto social e cultural da realidade histórica na interpretação proposta.

Além disso, tal tipo de abordagem resulta em uma representação demasiado estática do nosso passado colonial. Neste, segundo Boulos, os conflitos e problemas são rapidamente resolvidos em enfrentamentos armados ou por decisão da Coroa, há pouco espaço para negociação, adaptações, releituras, sejam das leis do rei, sejam das práticas e valores cristãos impostos. O processo histórico segue, linearmente, contado mais como realidade constituída do que como construção social. Assim, a obra parece, por vezes, flertar com o paradigma historiográfico "tradicional", historicista que, como nos ensina Peter Burke, entende a História como narrativa de acontecimentos.

O livro "Araribá mais: história", entretanto, aborda a catequese, as populações indígenas e a atuação da Companhia de Jesus no período colonial de maneira bastante diferente. As dimensões política, para além do âmbito institucional, e cultural da realidade histórica são amplamente abordadas, bem como adota-se uma perspectiva mais atenta às dinâmicas, concertos e desconcertos entre diferentes grupos sociais, entendendo-os como constituintes das realidades sócio-históricas.

Ao contrário dos livros das duas outras coleções, no "Araribá" um capítulo inteiro é dedicado a tratar dos povos nativos que se encontravam no atual Estado 
brasileiro quando da chegada e invasão portuguesa. Antes de tratar do encontro entre ameríndios e lusos, povos e universos culturais completamente diferentes, o livro aborda com riqueza de detalhes as culturas dos nativos do Brasil, suas formas de organização social, política, econômica, cultural, territorial, suas dinâmicas internas e seus valores. Trata largamente também das colaborações iniciais entre europeus e indígenas e de como estas se transformaram em conflito, face à escravização destes pelos portugueses. Ao destacar dois episódios específicos de guerras entre lusos e grupos nativos, entre elas a da Confederação dos Tamoios, a narrativa didática não só multiplica os protagonistas do processo de colonização, incluindo os indígenas, organizados entre si e combativos, como chama a atenção justamente para o caráter processual, negociado e dinâmico da história enquanto realidade vivida. Os jesuítas já aparecem nesses conflitos iniciais, como mediadores, enriquecendo a abordagem de um processo que foi complexo e envolveu muitos atores.

Também de maneira diversa aos outros dois livros, no da coleção “Araribá", o processo de catequese nos aldeamentos é apresentado em detalhes:

Para converter os povos nativos ao catolicismo, os jesuítas iniciaram, em várias partes da colônia, a organização de aldeamentos autossuficientes [...]. Nesses aldeamentos, os jesuítas trabalhavam para que os indígenas adotassem o modo de vida cristão e a adoração a um só Deus, deixando de lado a nudez, o politeísmo, as práticas poligâmicas, enfim, seus costumes ancestrais. Os jesuítas expandiram as missões para o sertão, atingindo [...] os atuais estados do Ceará, do Pará e do Maranhão. Na região da capitania de São Vicente, [...] e ao longo do rio Amazonas, foram estabelecidos muitos aldeamentos, alguns dos quais chegavam a reunir milhares de indígenas. Nas missões, os indígenas eram submetidos a uma rígida disciplina de oração e trabalho. Eles praticavam o artesanato, a agricultura, a caça, a pecuária e a coleta [...]. Os missionários impunham aos indígenas um modo de vida cristão e condenavam suas práticas e crenças tradicionais. Além disso, os catequizadores alteraram a estrutura social desses povos ao desvalorizar a função dos pajés e substituir seu tipo de moradia. Por isso, muitos nativos buscaram resistir à nova realidade [...]. (EDITORA MODERNA, 2018, p. 181-182)

Das três obras analisadas, esta é a que deixa mais clara a função de enquadramento e dominação cultural e política cumprida pela catequese e pelos aldeamentos, sem deixar de lado o caráter processual e negociado desse processo, uma vez que foi preciso combater crenças e costumes enraizados, desmontar e substituir estruturas sociais e políticas dos povos nativos, e enfrentar resistências, ainda que estas sejam pouco exploradas. De fato, é também apenas nesta obra que encontramos menção explícita (e não apenas nas orientações ao professor) à resistência indígena à catequese. E, ainda, ao contrário do que vemos em Boulos, a importância da atuação cultural e 
política dos agentes religiosos no assentamento e incorporação produtiva de milhares de indígenas à sociedade colonial é evidenciada, pois que os submetem à obediência pela oração e pelo trabalho, viabilizando a colonização.

Outro aspecto bem explorado na narrativa de "Araribá", mas pouco presente em "Vontade de Saber: história" e no livro de Boulos, é a atuação diversificada da Companhia de Jesus, sobretudo em atividades pedagógicas e em produções intelectuais junto a colonos e indígenas, aos quais os padres queriam igualmente enquadrar dentro dos costumes e valores da cultura católica europeia:

O ensino nos colégios jesuítas procurava seguir o mesmo padrão das escolas de Portugal. Os padres priorizavam a formação humanista, que abrangia conhecimentos nas áreas de gramática, retórica, música e poesia. Também eram oferecidos estudos de ciências, exercícios físicos e aulas de comportamento social. O principal objetivo era o de formar 'bons cristãos'. [...] As lições eram dadas em latim. [...] Já a educação indígena era realizada nas missões. Para possibilitar a catequese dos indígenas, os jesuítas realizavam encenações, aprendiam as línguas nativas e elaboravam dicionários e gramáticas nesses idiomas. (EDITORA MODERNA, 2018, p. 185)

Ainda que o objetivo final das atividades jesuíticas fosse o de formar "bons cristãos", o que não estava em desacordo com os propósitos da colonização portuguesa na América, a produção e a transmissão de saberes diversos, como poesia, ciência e música, e o desenvolvimento de atividades culturais em comunidade, como encenações teatrais, caracterizam uma narrativa sobre o nosso passado colonial na qual os horizontes de ação e interesse não se limitavam ao campo econômico ou políticoinstitucional. Ademais, essa perspectiva aponta uma certa autonomia dos sujeitos históricos frente aos interesses e ações do Estado.

Abordar os elementos e dinâmicas relativas às agências dos povos nativos e dos missionários aproxima, assim, a narrativa didática de "Araribá" do paradigma historiográfico da Nova História, que compreende a história vivida justamente como fruto das interações, enfrentamentos e transformações de vários grupos sociais, inclusive aqueles que foram dominados, de suas práticas, linguagens e mentalidades. $\mathrm{O}$ processo histórico da colonização é, assim, não dotado de sentido único e de desenvolvimento linear, mas significado na complexidade e diversidade de agências, de sujeitos, de intenções, interesses e interações, que se realizam conforme as possibilidades histórico-culturais e aquelas dadas pelas próprias interações.

Por fim, é preciso identificar e problematizar não mais uma diferença, mas um ponto em comum entre as três narrativas, a saber, a relação intrinsecamente conflituosa 
e de oposição entre colonos e jesuítas, associada a uma das características centrais da identidade jesuítica atribuída pela literatura didática em geral: a de protetores dos indígenas e defensores da sua liberdade.

A representação dessa relação é, nos três livros, dicotômica e plena de juízo de valor. A caracterização dos colonos traz em si uma carga negativa porque exploram o trabalho dos nativos e os escravizam, enquanto os jesuítas seriam, por oposição, boas pessoas, uma vez que protegem os indígenas da escravidão e garantem a sua liberdade e bem estar nos aldeamentos. Afinal, como lemos em "Vontade de Saber: história", "Os jesuítas se opunham à escravização dos indígenas e defendiam que eles fossem reunidos nas missões para serem catequizados" (DIAS, 2018, p. 168).

É claro que não propomos desconsiderar o compromisso da educação escolar com a formação ética voltada para o convívio democrático e republicano e que, para tanto, deve promover a crítica a atitudes contrárias aos direitos humanos, como a vida, a liberdade e a igualdade. Não é disso, porém, de que tratamos. A moralização do tema da escravização indígena leva à reprodução de uma tese já superada pela historiografia e à edificação de uma representação de certa forma heroicizada e, portanto, equivocada, dos jesuítas.

A tese de que os padres da Companhia de Jesus teriam sido moralmente contrários à escravidão indígena, de que foram defensores da liberdade dos índios, e de que os aldeamentos constituíram espaços de liberdade vem sendo questionada e matizada desde os anos 1990 pelas pesquisas de historiadoras e historiadores como Beatriz Perrone-Moisés, Luiz Felipe de Alencastro, Carlos Alberto Zeron, John Monteiro e Manoela Carneiro, estes dois últimos presentes na bibliografia de referência de "Vontade de Saber" e "Araribá". O que tem se demonstrado é que, ao contrário do que afirmam os livros didáticos, os jesuítas se utilizaram largamente do trabalho de escravizados, tanto ameríndios quanto africanos, a exemplo das demais ordens religiosas e dos colonos, e defenderam a subjugação e escravização dos nativos em determinados casos.

De acordo com a legislação portuguesa indigenista vigente entre os séculos XVI e XVIII, apesar das variações, a escravização indígena era considerada legítima em alguns casos específicos: resgate (em caso de ameaça à vida de quem seria escravizado), necessidade extrema (fome, incapacidade de se autossustentar) e guerra justa (motivada por recusa à conversão ou ataques injustos contra os portugueses). Os jesuítas não tiveram problema algum em apoiar iniciativas de combate a tribos hostis e sua 
escravização. Não só porque a escravização do corpo não comprometia a salvação da alma, como porque as ações da Companhia na América lusa também eram movidas por certo pragmatismo econômico e material. Os padres eram poucos e deveriam se dedicar às tarefas da catequese, da missionação e da educação dos colonos. Precisavam de mão de obra que os provesse do necessário para a sua subsistência. Como não tinham recursos, a princípio, para contratarem assalariados, necessitavam de escravizados. Em pouco tempo, o trabalho destes se tornou uma das fontes de financiamento da missão que, na prática, recebia parcos recursos da Coroa portuguesa, de acordo com o regime do padroado.

Portanto, a oposição dos jesuítas à escravização indígena praticada largamente pelos colonos, e que explica a maioria dos enfrentamentos travados entre estes grupos, não era uma oposição à escravização em si, motivada por questões morais, mas a sua aplicação em casos ilegítimos, que não previstos pela lei. Mas por que a adoção dessa postura legalista por parte dos religiosos? Isto se explica pelo fato de que, juridicamente, na época, a liberdade era entendida como um direito natural aos homens, derivado da lei divina, que estabeleceria os desígnios e intenções de Deus para o mundo e para a humanidade. Assim, a escravização não seria natural aos homens, não seria permitida por Deus, a não ser em circunstâncias específicas (as três acima comentadas). Para garantir o respeito ao direito natural da liberdade dos indígenas, um direito desdobrado da lei divina, os jesuítas argumentavam que apenas homens da Igreja poderiam arbitrar sobre a situação. Por isso, os indígenas trazidos das aldeias para serem integrados à sociedade colonial em formação deveriam ficar sob os cuidados dos padres, nos aldeamentos. Dito de outra maneira, os jesuítas não se opunham à escravização dos nativos em si, mas queriam ter o poder de determinar como estes seriam integrados, se como escravos ou aldeados, e ter o controle exclusivo destes últimos. Em um território no qual a força de trabalho indígena foi largamente utilizada até o século XVIII, ter o controle de uma parte expressiva dela dotava os controladores de grande poder e influência.

Para além disso, há um grave problema de incompreensão do sentido histórico do termo "liberdade natural" no que diz respeito aos ameríndios no período colonial. Aos olhos dos teólogos e juristas europeus dos séculos XV e XVI, e do próprio papado, apesar de sua rudeza e barbárie, os ameríndios seriam seres humanos livres e conscientes de seus atos. Portanto, não deveriam ser privados de seus direitos de domínio de seus bens e de sua liberdade. No entanto, seriam incapazes de exercê-los 
plenamente por serem considerados, em termos civis e jurídicos, como "menores". Neste caso, fazia-se necessária a supervisão e a proteção de seus interesses e a educação civil e religiosa dos nativos, ou seja, era necessário tutelá-los.

Assim, apesar de divulgarem amplamente no período colonial uma autorrepresentação de opositores da escravização nativa e defensores solitários e sacrificados da liberdade indígena, os jesuítas dissimulavam o fato de que, nos aldeamentos, os nativos e seus descendentes eram tutelados. Não se tratava de subtrair totalmente a autonomia dos mesmos, como na escravidão, mas, sem dúvida, era uma forma de controle, de restrição de liberdade e de exercício de autoridade sobre esses povos. Nos aldeamentos, os jesuítas eram responsáveis pela educação civil e religiosa dos indígenas, que se desenvolvia pela imposição da obediência às leis de Deus e do rei e por punições a desobediências, como a manutenção de seus costumes tradicionais, como a poligamia, o canibalismo e o politeísmo. Além disso, mediavam a contratação dos aldeados pelos colonos e o pagamento de salários, bem como exploravam a sua mão-de-obra na manutenção e abastecimento dos colégios e propriedades da Companhia.

Para além do aprofundamento da pesquisa histórica, o que parece importante a ser incorporado pela literatura didática é justamente o abandono da abordagem dicotômica e romantizada, comprometida com os discursos heroicizantes produzidos pelos próprios jesuítas, e anacrônica, visto que o entendimento da noção de "liberdade" varia historicamente, no tempo e nas circunstâncias. Se por um lado havia, grosso modo, dois projetos concorrentes de colonização no que tange a inserção do elemento nativo, como bem pontua Araribá, p.183, o dos jesuítas e o dos colonos, estes projetos não eram diametralmente opostos. Ambos consistiam em formas diferentes de controle, inserção social e exploração do trabalho indígena. E ambos impactaram de maneira negativa as culturas e a vida dos povos ameríndios, procurando destruir e transformar as suas formas de ser e viver. Nesse sentido, é preciso abrir mão dos eufemismos sobre esses impactos e da significação acrítica da catequese e do aldeamento como elementos promotores de liberdade e proteção, pois se tratam de reproduções de discursos dos próprios jesuítas, discursos que devem ser analisados e problematizados pelos historiadores e não reproduzidos.

Por outro lado, sobretudo após a lei 11.645, de 2008, parece fundamental também trazer para o primeiro plano a perspectiva dos nativos face ao processo de invasão de seus territórios pelos colonizadores portugueses. Além das constantes 
ameaças de escravização e exploração da sua força de trabalho, os indígenas também viveram a intensificação de conflitos entre si fomentados pelos lusos, interessados em resgatar e escravizar os prisioneiros dessas guerras tribais. Nesse sentido, face aos ataques dos portugueses e os conflitos com outras tribos, foram numerosos os casos de comunidades inteiras que aceitaram se integrar aos aldeamentos, considerando-os, frente às opções disponíveis, um mal menor.

\section{Possibilidades de aprendizagem e conscientização históricas}

A aprendizagem histórica, ou seja, o conhecimento e a compreensão das experiências humanas no tempo, se dá através de diversas vias. O ensino escolar da história é uma delas. Para muitos pesquisadores, o conhecimento histórico escolar, construído a partir da mobilização e mediação de diversos saberes feita pelos professores, ainda é preponderante no processo de aprendizagem. Nesse sentido, o livro didático, a despeito da multiplicação contemporânea das fontes de informação e interpretação sobre o passado, continua sendo uma ferramenta principal, não só no processo de aprendizagem, ao apresentar determinados conhecimentos históricos, como no de desenvolvimento da consciência histórica, ao apresentar determinados sentidos e significados para as experiências humanas no passado.

Considerando, portanto, as abordagens e sentidos atribuídos ao nosso passado colonial nos três livros analisados e, mais especificamente, às relações entre quatro "grupos"6 sociais centrais na sua constituição e desenvolvimento (representantes da Coroa portuguesa, colonos, jesuítas e indígenas), nos perguntamos que aprendizagens históricas são favorecidas por essas narrativas didáticas e, por conseguinte, que tipo de consciência histórica pode ser desenvolvida.

Como vimos, o livro de Alfredo Boulos para o $7^{\circ}$.ano da coleção "História sociedade \& cidadania”, em termos teórico-metodológicos, traz uma abordagem mais informativa e uma visão mais acontecimental e encadeada do passado, o que gera uma espécie de naturalização das explicações, distensionando processos históricos, como o da colonização portuguesa na América, que envolveu imposições, embates, reorganizações, negociações e acomodações de todos os envolvidos, dos muitos que

\footnotetext{
${ }^{6}$ Optamos pelo uso das aspas por entendermos que estamos arbitrariamente alocando sujeitos e grupos diversos em grandes categorias analíticas ("indígenas", "colonos", "representantes da Coroa", etc), mas o fazemos seguindo a própria categorização operada pelos livros didáticos.
} 
estavam na colônia, dos que estavam no reino e dos que transitavam entre esses dois espaços.

Como, em termos temáticos, observamos a predominância da dimensão econômica e político-administrativa da história colonial, a atuação dos jesuítas, ou agentes religiosos em geral, não tem muito espaço, bem como a dimensão cultural. Aos padres da Companhia é atribuída quase exclusivamente a tarefa da missionação, entendida como forma de colaboração ao projeto de colonização e exploração econômica da América pela Coroa lusa. Os sujeitos históricos, de maneira geral, não apresentam grande autonomia em seus interesses, projetos e ações, pois que o processo histórico se desenvolve essencialmente no eixo da exploração econômica, controlada pela Coroa, seus representantes e alguns grupos específicos de colonos, como os senhores de engenho, os grandes comerciantes e os bandeirantes. No que tange o processo missionário, quase não há conflitos ou negociações; ele é narrado de maneira estática, linear e pontual. O caráter de enquadramento político e cultural da catequese não é abordado, nem os impactos negativos da catequese para as populações indígenas. Pelo contrário. Os efeitos parecem positivos e aceitos pacificamente.

O baixo grau de problematização dos eventos que integram o processo de formação histórica da nossa sociedade, de complexificação das dimensões que compõem a realidade histórico-social, de variedade de sujeitos e pontos de vista favorecem uma aprendizagem histórica limitada e, portanto, o desenvolvimento de uma consciência histórica, de uma geração de sentido para o passado "tradicional", tomando a tipologia de Rüsen como referência. Ou seja, o passado tem uma significação unívoca (nesse caso, predominantemente econômica e político-institucional) e se desenvolveu linearmente até o presente, sem grandes percalços, impedimentos, conflitos, concertos ou negociações, apesar das transformações ocorridas ao longo do tempo, como que impulsionado por uma força que parece externa, alheia aos próprios homens e mulheres. Pensando no aspecto prático do desenvolvimento da consciência histórica, isto é, o de orientar os discentes na sua inserção e ação no presente e no futuro, essa forma de significação das experiências humanas no tempo, a qual a narrativa didática de Alfredo Boulos parece se associar, tende a favorecer uma postura de aceitação e naturalização da nossa sociedade tal como ela se apresenta, sem grandes críticas, e, portanto, um exercício mais passivo da cidadania pelos estudantes.

O livro da coleção "Araribá mais: história", ao contrário, traz uma visão mais rica, mais complexa e problematizadora do nosso passado colonial. Não só porque 
apresenta dimensões outras da realidade social que não só a econômica, e constrói uma interpretação do passado composta pelas ações e interesses de sujeitos e grupos sociais mais variados, que se combinam, se enfrentam e se articulam, multiplicando e complexificando a agência e o processo históricos, como porque dota a história vivida de um caráter processual e negociado não linear ou previsível, pois que fruto das interações sociais.

No caso da atuação dos jesuítas na América portuguesa, o destaque dado à variedade de atividades dos mesmos e ao sentido político-cultural atribuído à catequese, aos aldeamentos e à intermediação em geral praticada pelos padres entre lusos e nativos favorece uma aprendizagem histórica e sobre a realidade social que não limita os sujeitos a determinados papéis. Nesse caso, os agentes religiosos não limitavam as suas ações a tarefas ligadas às práticas e crenças religiosas, mas cumpriram um papel político fundamental, em geral alinhado à Coroa lusa, ao colaborarem diretamente para a ocupação territorial no litoral e no avanço para o interior, através do contato e negociação com as populações nativas, e promoção da integração subjugada das mesmas nos aldeamentos. Esse tipo de abordagem, que valoriza as dimensões políticas e culturais da vida em sociedade, favorecem a compreensão da história como dinâmica, como movimento, como conjugação de tensões e concertos protagonizados por agentes variados, e não apenas pelos que detinham poder institucional ou poder econômico. Salientar as resistências dos indígenas à catequese fortalece esse tipo de aprendizagem. $\mathrm{Na}$ visão do passado colonial apresentada em “Araribá”, indígenas, missionários e colonos também participam da construção de uma sociedade colonial que não se limitava ao litoral açucareiro, nem à escravização africana ou aos interesses da Coroa portuguesa e dos senhores de engenho, concepção de passado que ainda encontramos em muitos livros didáticos de História, inclusive no de Alfredo Boulos.

Entendemos, assim, que o livro da coleção "Araribá" propicia o desenvolvimento de uma consciência histórica crítico-genética, ainda segundo a tipologia de Rüsen, ao apresentar a experiência colonial como também tendo sido constituída de interações conflituosas, rupturas, de contradições da norma, sobretudo se pensarmos, por exemplo, nas resistências indígenas, nos confrontos, ainda que romantizados, mas existentes, entre jesuítas e colonos pelo controle das populações nativas. E, ainda, ao representá-la como múltipla e diversa em seus sujeitos, que, em suas ações, trazem consigo seus pontos de vista, valores, desejos e projetos. Essa perspectiva sobre o passado apresentada pelo livro didático favorece, sem dúvida, uma 
significação mais complexa da experiência humana no tempo, constituída por interações de tipos variados, embates, rupturas, disputas, por dinâmicas, mudanças e diversidade. A partir dessa perspectiva sobre o passado, pode-se desenvolver um olhar para o presente mais problematizador, mais atento às ações, valores, interesses e propostas de sujeitos vários, bem como às suas disputas, entendendo a realidade histórica e social como fruto de interações, conflituosas ou não, e, assim, se promover um exercício mais ativo e engajado da cidadania.

\section{Considerações finais}

De toda a maneira, o debate sobre as possibilidades de aprendizagem histórica e desenvolvimento da consciência histórica a partir das narrativas didáticas deve necessariamente se articular ao debate sobre a formação do historiador e professor de história. Tendo em vista o largo alcance e penetração entre os milhões de brasileiros com acesso à educação escolar dos livros didáticos, alcance potencializado pelo PNLD, e considerando, como fizemos na análise apresentada, as diferentes concepções sobre o passado que veiculam, parece fundamental chamar a atenção para a necessidade de uma formação docente assentada em sólida formação teórico-metodológica do historiador. Sendo os livros didáticos produtos culturais e fontes de conhecimento histórico, trazem em si uma historicidade e pontos de vista específicos sobre o passado, mas não únicos. Cabe, assim, à formação docente desenvolver nos licenciandos a capacidade de leitura e apropriação crítica desta fonte e a sua conjugação com outras que julgar pertinentes de modo a favorecer entre os alunos da educação básica uma aprendizagem histórica crítica e problematizadora e uma postura ativa e propositiva em sociedade.

\section{Referências}

ABREU, Martha; SOIHET, Rachel (orgs.). Ensino de História: conceitos, temáticas e metodologia. Rio de Janeiro: Casa da palavra, 2003.

ABUD, Kátia. Processos de construção do saber histórico escolar. História \& Ensino, Londrina, v. 11, p. 25-34, 2005.

ALENCASTRO, Luiz Felipe de. O trato dos viventes: a formação do Brasil no Atlântico Sul. São Paulo: Cia. das Letras, 2000.

BOULOS JÚNIOR, Alfredo. História sociedade \& cidadania: $7^{\circ}$.ano. São Paulo: FTD, 2018. 
BRASIL. Ministério da Educação. PNLD 2020: história - guia de livros didáticos/ Ministério da Educação - Secretaria de Educação Básica - Fundo Nacional de Desenvolvimento da Educação. Brasília, DF: Ministério da Educação, Secretaria de Educação Básica, 2019.

BURKE, Peter (org.). A escrita da História: novas perspectivas. São Paulo: Ed. Unesp, 1992.

CERRI, Luís Fernando. Ensino de história e consciência histórica. Rio de Janeiro: Editora FGV, 2011.

COELHO, Mauro Cezar. Que enredo tem essa história? A colonização portuguesa na América nos livros didáticos de história. In: ROCHA, Helenice; REZNIK, Luís; MAGALHÃES, Marcello. Livros didáticos de história: entre políticas e narrativas. Rio de Janeiro: FGV Editora, 2017.

CORRÊA, Dora. Historiadores e cronistas e a paisagem da colônia Brasil. Revista Brasileira de História. São Paulo, v. 26, n. 51, p. 63-87, 2006.

CUNHA, Manuela Carneiro da, (org.). História dos Índios no Brasil. São Paulo: Cia. das Letras, 1992.

DIAS, Adriana Machado; GRINBERG, Keila; PELLEGRINI, Marco César. Vontade de Saber: história: $7^{\circ}$.ano. São Paulo: Quinteto Editorial, 2018.

EDITORA MODERNA. Araribá mais: história: $7^{\circ}$ ano. São Paulo: Moderna, 2018.

FONSECA, Selva G. Livros didáticos e paradidáticos de história. In: Didática e prática de ensino de história. Campinas: Papirus, 2003.

FONSECA, Thaís N. de Lima. História e ensino de história. Belo Horizonte: Autêntica, 2006.

GAGO, Marília. Concepções de passado como expressão de consciência histórica. Currículo sem Fronteiras, v. 7, n. 1, p. 127-136, jan/jun 2007.

MEDEIROS, Daniel. A formação da consciência histórica como objetivo do ensino de história no ensino médio: o lugar do material didático. Tese (Doutorado em Educação), Universidade Federal do Paraná, Curitiba, PR, 2005.

MIRANDA, Sônia; DE LUCA, Tânia. O livro didático de história hoje: um panorama a partir do PNLD. Revista Brasileira de História, São Paulo, v. 24, n. 48, p.123-144, 2004.

MONTEIRO, John. Negros da terra. Índios e bandeirantes nas origens de São Paulo. São Paulo: Companhia das Letras, 1994.

PERRONE-MOISÉS, Beatriz. Índios livres e índios escravos: os princípios da legislação indigenista do período colonial (séculos XVI a XVIII). In: CUNHA, M.C. da (org.). História dos Índios no Brasil. São Paulo: Companhia das Letras, 1992. 
PRADO JÚNIOR, Caio. Formação do Brasil Contemporâneo. São Paulo: Ed. Brasiliense, 1953.

RÜSEN, Jörn. Teoria da história. Brasília: UnB, 2007.

SCHMIDT, Maria Auxiliadora; GARCIA, Tânia. A formação da consciência histórica de alunos e professores e o cotidiano em aulas de história. Caderno Cedes, Campinas, v. 25, n. 67, p. 297-308, set./dez. 2005.

SCHMIDT, Maria Auxiliadora; URBAN, Ana Claudia. Aprendizagem e formação da consciência histórica: possibilidades de pesquisa em Educação Histórica. Educar em Revista, Curitiba, n. 60, p. 17-42, abr./jun. 2016.

SKINNER, Quentin. As fundações do pensamento político moderno. São Paulo: Companhia das Letras, 1996.

VAINFAS, Ronaldo; SILVA, Georgina. Igreja, Inquisição e religiosidades coloniais. In: FRAGOSO, João; GOUVÊA, Maria de Fátima. Brasil Colonial, v.1. Rio de Janeiro: Civilização Brasileira, 2014.

ZERON, Carlos Alberto. O debate sobre a escravidão ameríndia e africana nas universidades de Salamanca e Évora. In: CAMENIETZKI, Carlos Ziller; CAROLINO, Luis Miguel (orgs.). Jesuitas, Ensino e Ciência. Séculos XVI-XVIII. Casal de Cambra: Caleidoscópio, 2005.

Linha de Fé. A Companhia de Jesus e a Escravidão no processo de formação da sociedade colonial (Brasil, séculos XVI e XVII). São Paulo: Edusp, 2011.

Artigo recebido em 21 de junho de 2020. Aprovado em 23 de julho de 2020. 